\title{
P-wave tomography and relation between shallow and deep structures beneath the Songliao basin
}

\author{
Qiyan Yang $\cdot$ Qingju Wu $\cdot$ Xiaojun Ma $\cdot$ Fengxue Zhang $\cdot$ Yanrui Sheng
}

Received: 17 December 2014/ Accepted: 16 April 2015/Published online: 6 August 2015

(C) The Author(s) 2015. This article is published with open access at Springerlink.com

\begin{abstract}
We selected relative travel-time residuals from teleseismic waveform data using the waveform correction method and imaged the $\mathrm{P}$ wave velocity structure beneath Northeast China. In combination with other geophysical data, we discussed the relation between the shallow and deep structures of the area. The results show that there is a primary high-velocity zone with some high- and low-velocity distribution characters beneath the Songliao basin. The low-velocity anomalies may extend down to the upper mantle, and may be the result of material upwelling. The low-velocity anomaly beneath the southern part of the Songliao basin is connected to those beneath the Changbaishan and A'ershan volcanic areas. It may be an upwelling channel from the mantle beneath the Songliao basin and adjacent area. This finding indicates the Songliao basin was a result of asthenospheric upwelling caused by subduction of the Pacific plate under the Eurasian plate.
\end{abstract}

Keywords Tomography - Northeast China - Ray · Relation between shallow-deep structures

Q. Yang · Y. Sheng

Earthquake Administration of Hebei Province,

Shijiazhuang 050021, China

Q. Yang · Q. Wu $(\bowtie) \cdot$ X. Ma · F. Zhang

Institute of Geophysics, China Earthquake Administration,

Beijing 100081, China

e-mail: wuqj@cea-igp.ac.cn

X. Ma

Earthquake Administration of Ningxia Autonomous Region,

Yinchuan 751000, China

\section{Introduction}

The Songliao basin is in the center of the Northeast China region, with the Central Asian fold belt (the Great Xing'an Range) to the west, the uplifted Changbaishan volcanic region to the east, and the Sino-Korean Craton to the south. The Songliao basin is commonly believed to be formed due to rifting in the Mesozoic Era (Hu et al. 1998; Ren et al. 2001; Liu and Niu 2011). In recent years, some studies have used tomography (P wave, Pn wave, $\mathrm{S}$ wave, and ambient noise), receiver functions, and $\mathrm{S}$ wave attenuation to reveal deep dynamic characteristics in the area (Zhao 2004; Lei and Zhao 2005; Sun 2012; Zhang et al. 2013, 2014; Pan et al. 2014). The previous research has shown that the Songliao basin was probably formed as a result of rifting during the Mesozoic. The eastern margin of the Songliao basin, where Cenozoic volcanism is active, has a relatively thin crust, with a upwelling channel of material from the mantle. The lithospheric mantle possibly underwent destruction and transformation, and lithospheric delamination may have occurred and greatly affected the Songliao basin (Song et al. 2010; Yu et al. 2012). Other studies have used the Bouguer gravity anomaly (Wei et al. 2014), magnetic (Shu et al. 2003), geothermal (Shi 2004), seismic and geological profiles (Wan 2012) to study the tectonic evolution of the Songliao basin. The dynamic studies paid more attention to the deep mantle structure beneath the basin; while tectonic evolution studies focused on shallow structure change. However the relation between shallow and deep structures in Songliao basin still remains poorly understood. In this study, we investigated lateral and vertical variations of the mantle using $\mathrm{P}$ wave tomographic data and other geophysical results to determine the relation between the shallow and deep structures beneath the Songliao basin. 


\section{Seismic data and method}

The recent release of broadband waveform data of permanent regional seismic networks in Northeast China from the China Earthquake Administration (CEA) (Zheng et al. 2009), from the NECESSA Array, and from our temporary networks provided a rare opportunity to investigate the crustal structure of this area. There were a total of 137 CEA broadband stations, 129 NECESSA Array stations, and 116 temporary stations in the study area $\left(115^{\circ} \mathrm{E}-135^{\circ} \mathrm{E}\right.$ and $38^{\circ} \mathrm{N}-52^{\circ} \mathrm{N}$ ) (Fig. 1). We collected waveform data from 606 earthquakes of magnitude $M_{\mathrm{S}} \geq 5.0$ occurred between May 2009 and August 2011 recorded at an epicentral distance of $30^{\circ}-90^{\circ}$ (Fig. 2).

The criteria used to select teleseismic events were as follows: (1) events should have an epicentral distance of $30^{\circ}-90^{\circ}$ and try to avoid effects of mantle and complex structure of the core-mantle boundary on seismic wave travel time; (2) events should have magnitude greater than $M_{\mathrm{S}} 5.0$ to ensure that the seismic waves arrived at stations with a high signal-to-noise ratio; (3) there should be more than 10 records for each event. After selection, we performed the following pretreatments on the data: RMEAN, RTREND, and band-pass filter with frequencies range from $0.02 \sim 0.1 \mathrm{~Hz}$. We also used the wave cross-correlation method (VanDecar and Crosson 1990; Rawlinson and Kennett 2004) to pick up the residuals. Finally, we visually checked all the seismograms and selected a total of 90,724 usable relative travel-time residuals.

This study uses seismic ray travel-time tomography to study the velocity structure of Northeast China. This method involves the following steps: firstly subdivide the research region and mesh the grid; secondly pick up ray travel time in seismic data, seismic ray tracking; thirdly build the inversion equation and solve the matrix equation; and finally evaluate the results of resolution and reliability. The results provide some reliable velocity anomaly characteristics and provide good constraints for the solution of these velocity anomalies to elucidate basin formation and the geodynamic process. In this article, our main focus is $\mathrm{P}$ wave velocity abnormal structures.

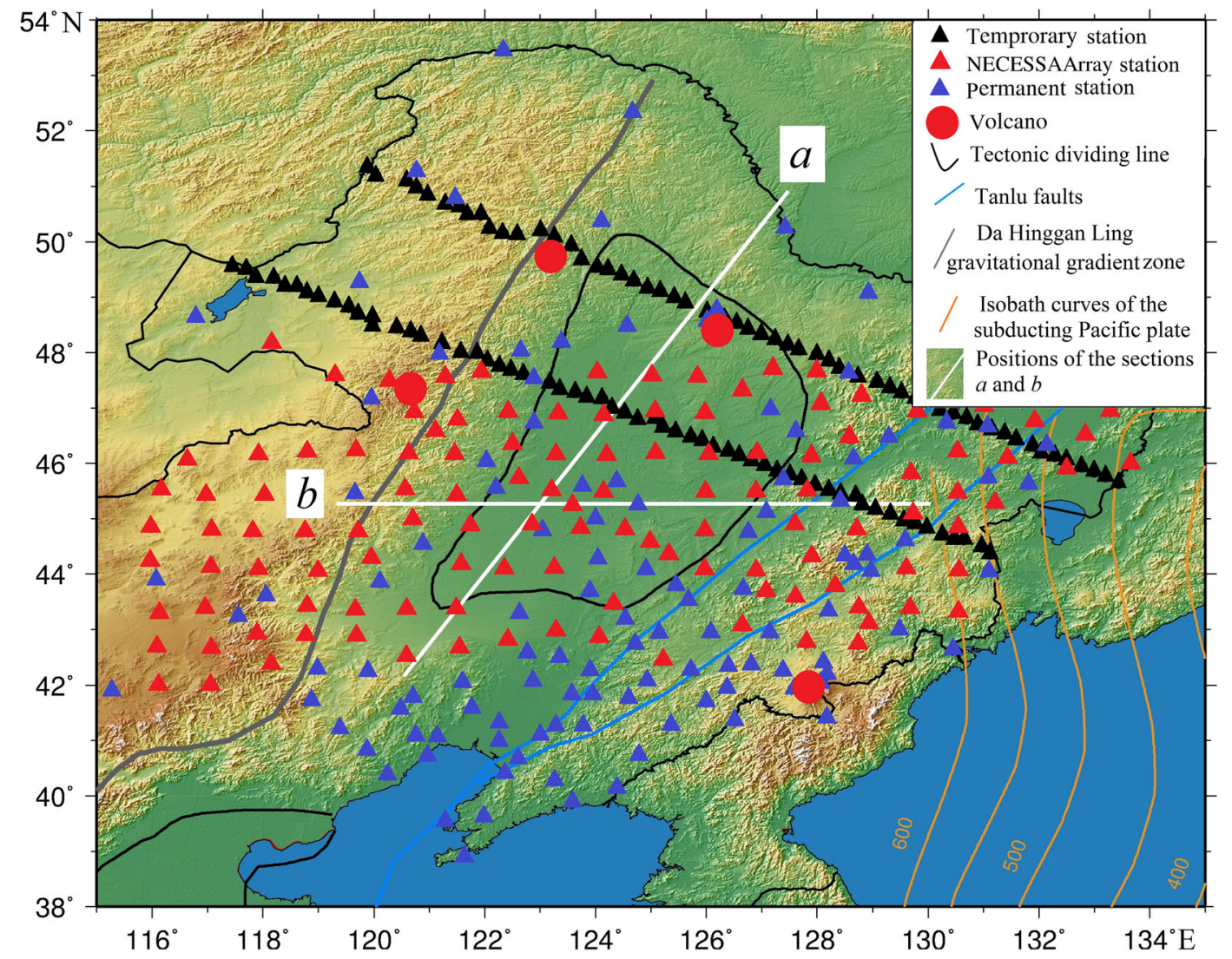

Fig. 1 Tectonic setting and station distribution in the studied area 


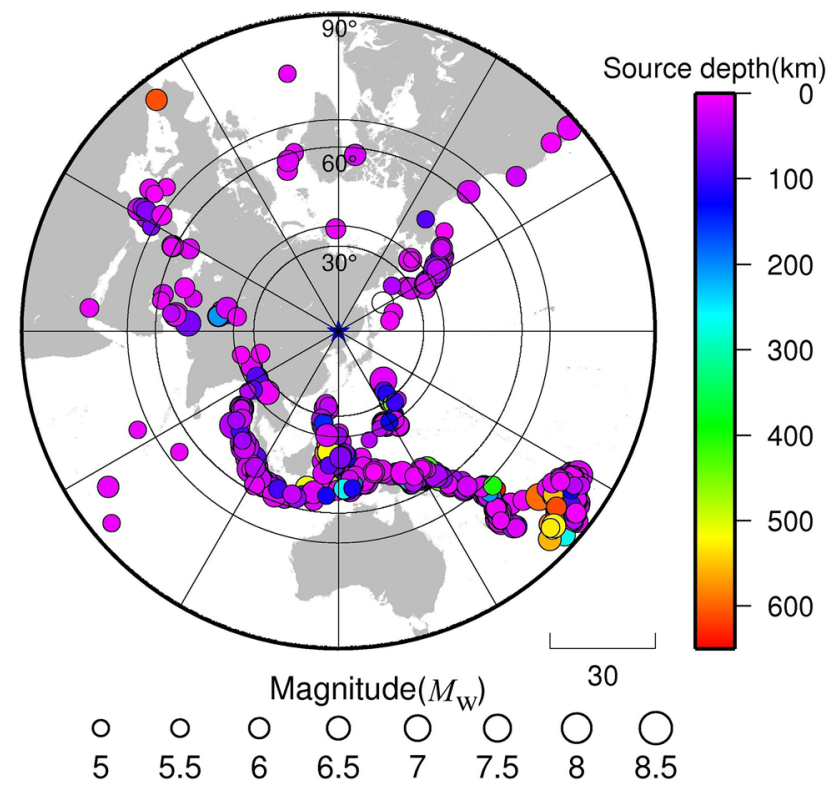

Fig. 2 Distribution of teleseismic events in the study

\section{Reliability analyses of inversion results}

\subsection{Multi-channel cross-correlation, damping coefficient, and residual analyses}

To validate the multi-channel cross-correlation results, we obtained the travel-time residuals from the original data. The stack results obtained using multi-channel cross-correlation is shown in Fig. 3. It shows that the cross-correlation results are reliable. We adopted the LSQR method (Paige 1982) with damping inversion. The damping coefficient in the algorithm controls the convergence speed and constrains the smoothness of the model. From the trade-off curve (Fig. 4) of model variance and travel-time residual variance for different values of damping coefficient, it can be found apparently when the damping coefficient is 20 , the model is relatively smooth and the mean square is relatively small. Thus, in the inversion, we adopted a damping coefficient of 20.

Figure 5 shows the distributions of the relative traveltime residuals before and after inversion. The relative travel-time residuals before the inversion are most focused on the time period $-1.0 \mathrm{~s}$ to $1.0 \mathrm{~s}$. After inversion, the residual distribution has a smaller range, with most values lying between $-0.4 \mathrm{~s}$ and $0.4 \mathrm{~s}$, and has the characteristics of a normal distribution.

\subsection{Resolution tests}

Several inversion results could be obtained for multiplicity. Thus, we performed a checkerboard test to verify inversion

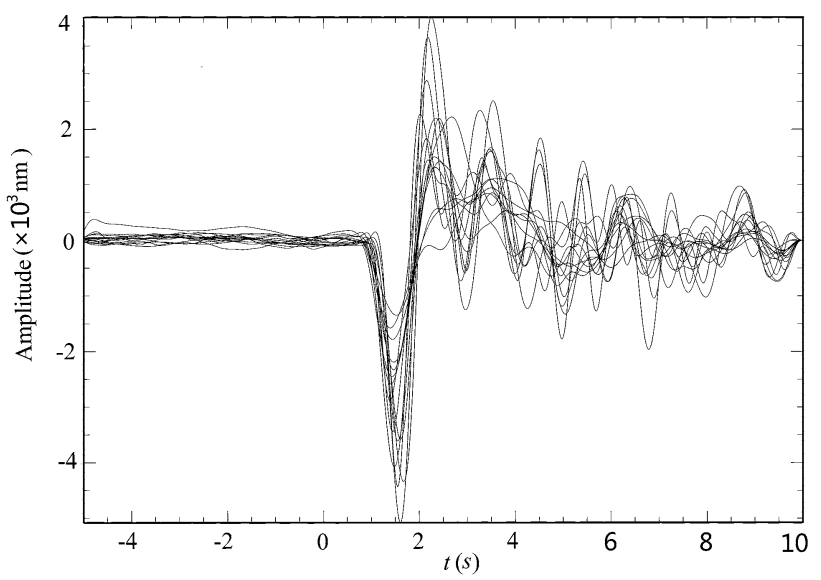

Fig. 3 Stack results obtained using multi-channel cross-correlation

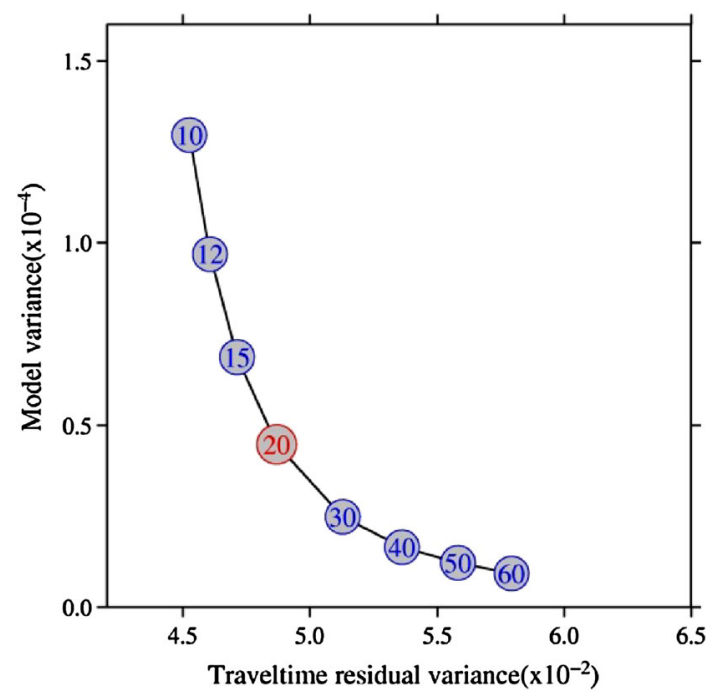

Fig. 4 Tradeoff curves of model variance and travel-time residual variance for different values of damping coefficient (values shown in circles)

results to show the reasonable $\mathrm{P}$ wave structure beneath the studied area. The checkerboard test process is as follows: we firstly built an initial model I and created a disturbance model II in which positive and negative velocity anomalies are increased or reduced respectively on the basis of the initial velocity model I. Secondly using the relative residual mentioned above as the observation, we take the model II as the initial model for imaging inversion, and take the inversion result as the model III. Finally, we compared abnormal scale between models II and III, and the minimum abnormal body should be the resolution. In this study, we firstly created checkerboard anomalies alternating between $3 \%$ faster and slower velocity anomalies. The studied area was separated into several blocks and the size of each block is approximately $50 \mathrm{~km} \times 60 \mathrm{~km}$. We then 

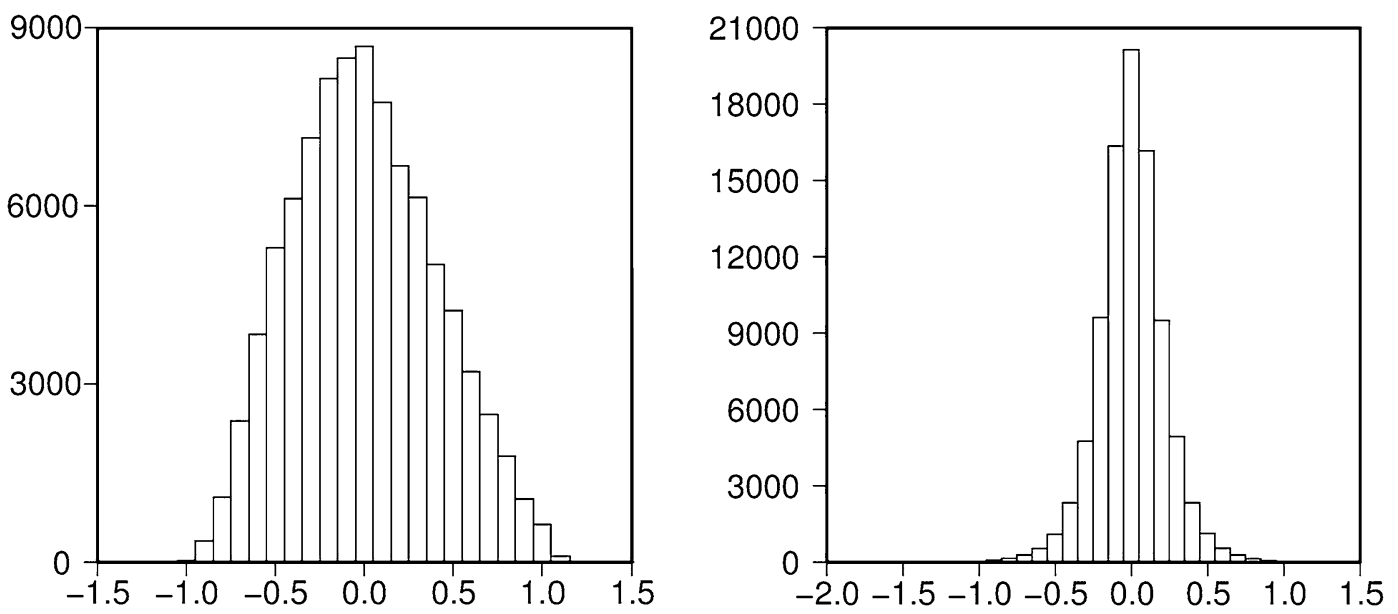

Fig. 5 Distributions of the relative travel-time residuals before (left) and after (right) inversion

generated a synthetic travel-time dataset using earthquakes and stations identical to that of the observed differential travel-time data. Random noise ranging from $-0.15 \mathrm{~s}$ to $0.15 \mathrm{~s}$ was added to the synthetic data. Figure 6 shows the results of the recovered checkerboards at eight different depths. The checkerboard model fit well in the depth less than $800 \mathrm{~km}$. The largest and the smallest blocks are $16.0^{\circ} \times 20.0^{\circ}$ and $0.500^{\circ} \times 0.625^{\circ}$ laterally and $800 \mathrm{~km}$ and $50 \mathrm{~km}$ vertically. The study region was parameterized with the smallest blocks. The test indicates that the $\mathrm{P}$ wave travel-time data have good resolution at length scales of approximately $200 \mathrm{~km}$ in the study region. Note that the amplitudes of the velocity anomalies in the recovered model decay steadily with depth. For structures below $400 \mathrm{~km}$ depth, significant smearing occurs at the edge of the study area, and the recovered velocity perturbations are less than half of the input values.

\section{Results and discussion}

There have been many studies on seismic structure of the Songliao basin. Liu and Niu (2011) found that the crustal thickness varies from $27.9 \mathrm{~km}$ beneath the eastern flank of the Songliao basin to $40.7 \mathrm{~km}$ beneath the Da Hinggan Ling region and suggested there would be a mantle upwelling using tele-seismic receiver function method. Zhang et al. (2013, 2014) found there is a high-velocity zone beneath the Songliao basin with some high- and lowvelocity anomalies using tele-seismic tomographic data. The low-velocity anomaly was found at the depth of $400 \mathrm{~km}$ beneath the southern part of the Songliao basin. Tele-seismic receiver function and seismic images studies by Tang et al. (2014) also verified this characteristics of high- and low-velocities anomalies distributed jointly in the depths of $100 \mathrm{~km}$ and $260 \mathrm{~km}$ and low velocities zone at the depth of $420 \mathrm{~km}$ beneath the Songliao basin.

We selected the one-dimensional Earth velocity model IASP91 (Kennett and Engdahl 1991) as the initial test model, and adopted travel-time tomographic inversion of $\mathrm{P}$ wave to image the velocity structure. The imaging results for each depth are shown in Fig. 7. The Tanlu faults and the gravitational gradient zone are roughly the east and west boundaries of the Songliao basin, which is basically consistent with the main boundaries of the velocity anomalies. The region of Northeast China can be divided into three parts: east, middle, and west zones by velocity anomaly. The east and west zones are low-velocity anomalies: Changbaishan and A'ershan, respectively. The middle zone is the Songliao basin; in which there is some high- and low-velocities anomalies in the background of high-velocity zone. The high-velocity zone mainly distributes from depth of $50 \mathrm{~km}$ to $600 \mathrm{~km}$, while the lowvelocity anomalies zones mainly concentrate from depth of $50 \mathrm{~km}$ to $400 \mathrm{~km}$. We also determined one low-velocity anomaly zone at the center of the Songliao basin in depth of $50-100 \mathrm{~km}$ and some low-velocity anomalies zones in the north and south of the Songliao basin with depths range from $150 \mathrm{~km}$ to $400 \mathrm{~km}$. We deduced that the low-velocity anomalies extend down to the upper mantle, which may be the result of mantle material upwelling. Our results are similar to, but not completely consistent with, the other studied results ( $\mathrm{Li}$ et al. 2006; Li and van der Hilst 2010; Wei et al. 2012; Zhang et al. 2013, 2014). The mixture of high and low-velocity anomalies suggests that the lithospheric mantle may have been destroyed and transfered, and hence the formation of the Songliao basin may have been greatly affected by lithospheric delamination. The low-velocity anomaly beneath the southern part of the Songliao basin area is connected to the those beneath the Changbaishan and A'ershan volcanic areas. This result 



Fig. 6 Results of the checkboard resolution test of depth of $50 \mathrm{~km}(\mathbf{a}), 100 \mathrm{~km}(\mathbf{b}), 150 \mathrm{~km}(\mathbf{c}), 200 \mathrm{~km}(\mathbf{d}), 300 \mathrm{~km}(\mathbf{e}), 400 \mathrm{~km}(\mathbf{f}), 500 \mathrm{~km}$ (g) and $600 \mathrm{~km}(\mathbf{h})$. The blue and red stand for high- and low-velocities, respectively. The purple lines are gravitational gradient zone. The black lines represent the Tanlu faults; The gray lines represent the the tectonic dividing line; The blue lines represent the isobath curves of the subducting Pacific plate, the red dots stand for the volcano and the black triangles denote stations 

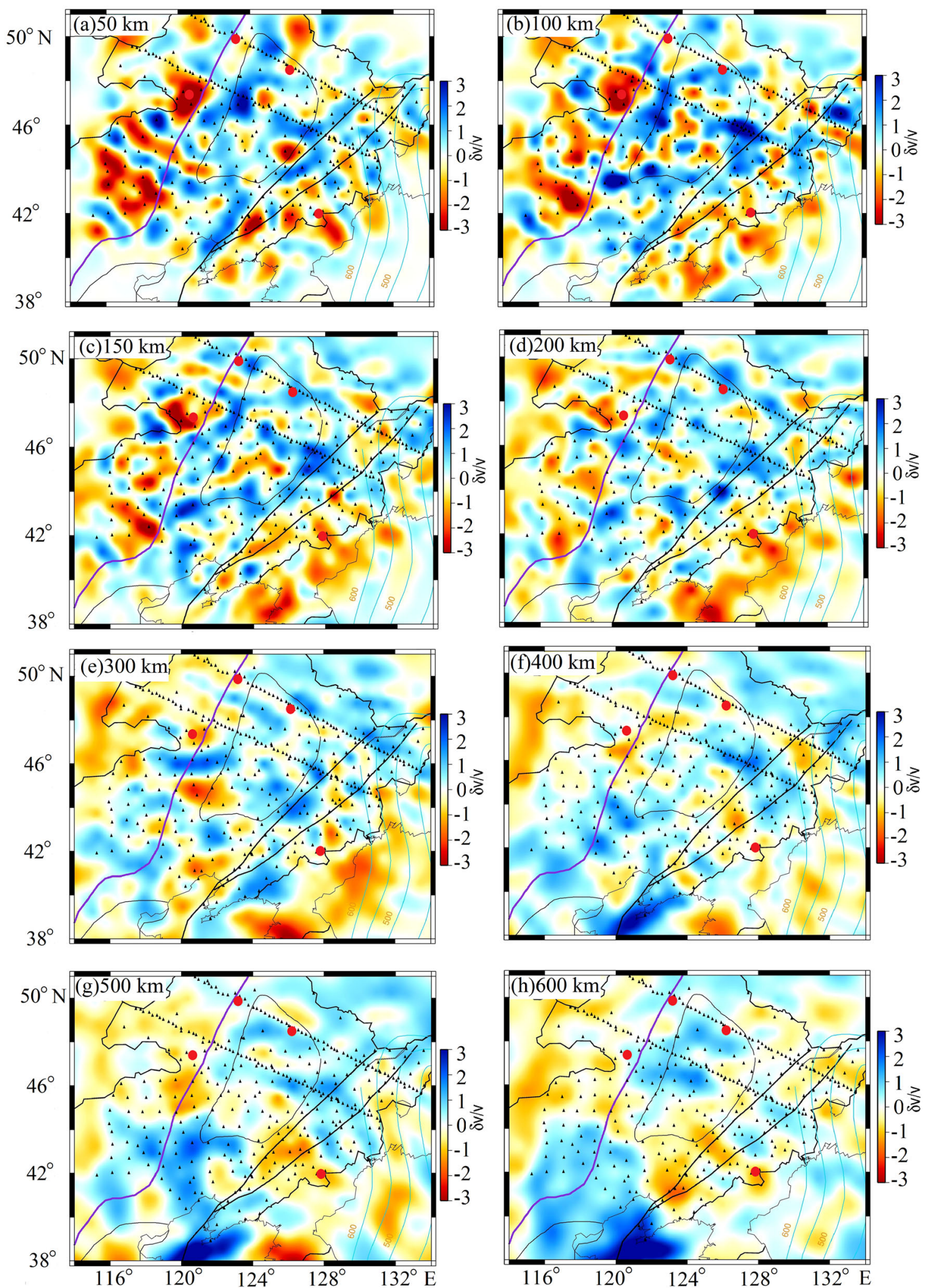

Fig. 7 Velocity structure of depth of $50 \mathrm{~km}(\mathbf{a}), 100 \mathrm{~km}(\mathbf{b}), 150 \mathrm{~km}(\mathbf{c}), 200 \mathrm{~km}(\mathbf{d}), 300 \mathrm{~km}(\mathbf{e}), 400 \mathrm{~km}(\mathbf{f}), 500 \mathrm{~km}(\mathbf{g})$ and $600 \mathrm{~km}(\mathbf{h})$ inverted using $\mathrm{P}$ wave travle-time tomography. The blue and red stand for high- and low-velocities, respectively. The purple lines are gravitational gradient zone. The black lines represent the Tanlu faults; The gray lines represent the the tectonic dividing line; The blue lines represent the isobath curves of the subducting Pacific plate, the red dots stand for the volcano and the black triangles denote stations 


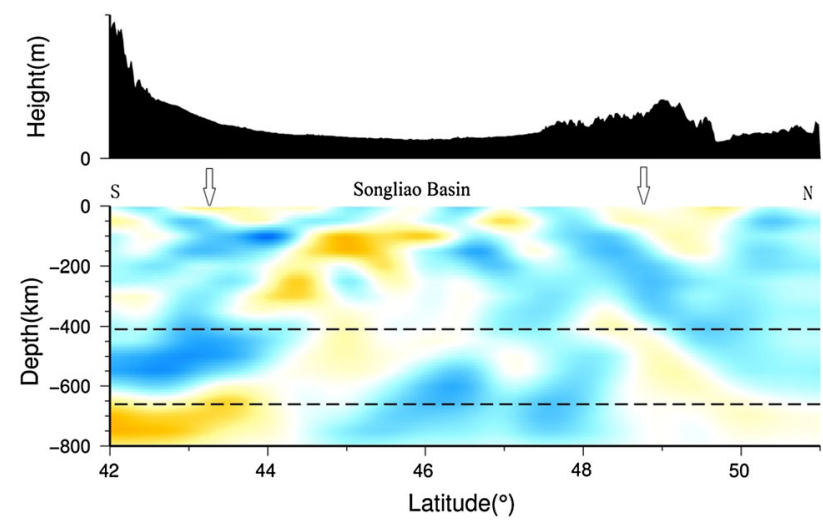

Fig. 8 Vertical section across the Songliao basin from south to north (line $a$ in Fig. 1) $\left(42^{\circ} \mathrm{N}, 120^{\circ} \mathrm{E}\right)$ to $\left(51^{\circ} \mathrm{N}, 129^{\circ} \mathrm{E}\right)$. The upper figure shows the topographical relief in this vertical section; the lower is the velocity anomaly imaging inverted by tomography. Dashed lines are the $410 \mathrm{~km}$ and $660 \mathrm{~km}$ discontinuities, the arrow in the figure give the boundary of the basin

reveals that there is an upwelling material channel from the mantle beneath the Songliao basin and its surrounding area.

As mentioned above, although many studies have been performed in the Songliao basin using various geological and geophysical methods (Shu et al. 2003; Zhao 2004; Lei and Zhao 2005; Sun 2012; Wan 2012; Zhang et al. 2013, 2014; Pan et al. 2014; Wei et al. 2014), the relation between shallow and deep structures in the Songliao basin still remains poorly understood. Figures 8 and 9 show the topographical relief and imaging inverted by tomography of two vertical sections across Songliao basin from $\left(42^{\circ} \mathrm{N}\right.$, $\left.120^{\circ} \mathrm{E}\right)$ to $\left(51^{\circ} \mathrm{N}, 129^{\circ} \mathrm{E}\right)$ and $\left(45^{\circ} \mathrm{N}, 119^{\circ} \mathrm{E}\right)$ to $\left(45^{\circ} \mathrm{N}\right.$, $\left.130^{\circ} \mathrm{E}\right)$, respectively. The figures suggest the Changbaishan maybe a result of mantle material upwelling originated from depth near $700 \mathrm{~km}$. The receiver function results shows obvious lateral variation in the upper mantle transition zone, which maybe result from mantle material upwelling (Liu and Niu 2011; Tang et al. 2014). The geothermal gradient of the Songliao basin which has a high heat value, is slightly higher than that of other basins elsewhere in the world (Nie 2004). The strain fields of Northeast and North China show NW-SE extension is weaken from east to west. The maximum strain occurs in the middle of the Tanlu fault zone, which is the boundary of the Songliao basin (Li 2013). The subducting Pacific slab and the mantle upwelling may have a remote effect.

The suggestion of mantle material upwelling is consistent with fact that in the eastern margin of Songliao basin, Cenozoic volcanism is active and crust is thin. Despite the relatively high altitude in the region, the Songliao basin has a relatively thin crust, which is probably related to Mesozoic rifting (Liu and Niu. 2011). The previous studies (Liu and Niu 2011; Gao and Li 2014; Pan et al. 2014; Wei et al.

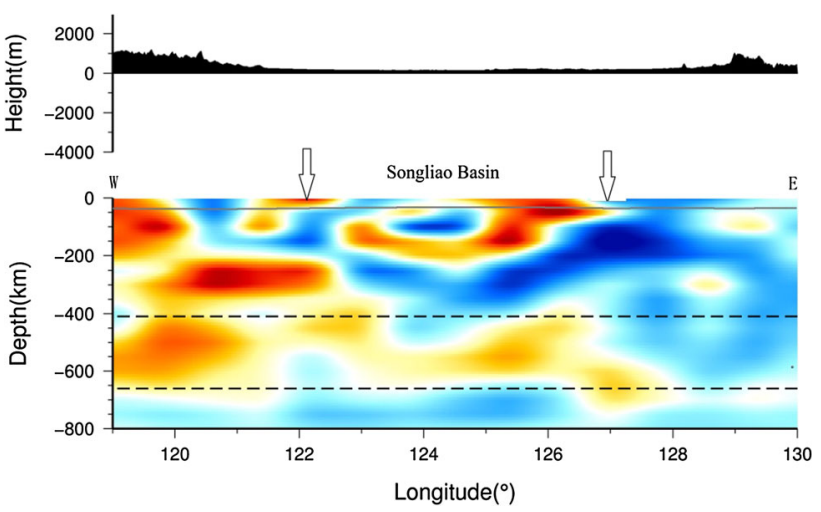

Fig. 9 Vertical section across the Songliao basin from west to east (line $b$ in Fig. 1) $\left(45^{\circ} \mathrm{N}, 119^{\circ} \mathrm{E}\right)$ to $\left(45^{\circ} \mathrm{N}, 130^{\circ} \mathrm{E}\right)$. The upper figure shows the topographical relief in this vertical section; the lower figure is the velocity anomaly imaging inverted by tomography. Dashed lines are 410 and $660 \mathrm{~km}$ discontinuities, the arrow in the figure give the boundary of the basin

2014) suggested that variations in crustal thickness apparently play an important role in controlling tectonic activity in the study region. Studies of the regional variations in crustal attenuation in Northeast China and the adjacent regions shows that the highest attenuation (low $Q_{0}$ values) is observed beneath the Songliao plain, which has thick sedimentary deposits and strong tectonic activity (Sun 2012). The structure of the crust in the North Songliao basin, inferred from the Bouguer gravity anomaly, is divided into three layers: upper, middle, and lower crusts (Wei et al. 2014). The seismic profiles through the two uplifts of the Songliao basin show that the crustal structure has strong vertical and lateral heterogeneities; obvious differences can be observed between the upper and lower crustal reflections (Yang et al. 2003). This result reveals that the Songliao basin experienced multistage tectonic activities, while the distribution of basalt magma in the basin possibly confirms the existence of an upwelling material channel from the mantle that affected both the crust and the tectonic activity.

Our results indicate that the formation and evolution of the Songliao basin were related to the subduction of the Pacific plate under the Eurasian plate as well as asthenosphere upwelling, both of which produced jointly crustal extension. The subduction induced one-way circulation of the asthenosphere and diapirism of the mantle magma, leading to stretching and thinning of the lower crust under the shearing action and brittle stretching of the upper crust to form a rift basin. As the subduction of the west Pacific plate steepened, the subduction zone retreated eastward and the melted mantle material extended continuously eastward. As the mantle cooled, the Songliao basin subsided and developed into a depression basin. 


\section{Conclusions}

We selected relative travel-time residuals from teleseismic waveform data using the waveform correction method and obtained 90,724 usable relative travel-time residuals. The teleseismic waveform data were recorded by a total of 382 stations in one permanent and two temporary networks in Northeast China. We used the data to image the $\mathrm{P}$ wave velocity structure beneath Northeast China.

The results show that mostly a high-velocity zone exists with many high and low velocity anomalies areas beneath the Songliao basin. The low-velocity anomalies may extend down to the mantle and are possibly induced by material upwelling. The distribution of high and low velocity anomalies suggests that the lithospheric mantle possibly experienced destruction and transformation, and the formation of Songliao basin was possibly greatly affected by lithospheric delamination. The low-velocity anomaly beneath the southern part of the Songliao basin is connected to the low-velocity anomalies beneath the Changbaishan and A'ershan volcanic areas.

Formation and evolution of the Songliao basin were caused by subduction of the Pacific plate under the Eurasian plate, which induced asthenospheric upwelling and hence crustal extension. This induced one-way circulation of the asthenosphere, and the diapirism of the mantle magma led to stretching and thinning of the lower crust as a result of shearing. Brittle stretching of the upper crust formed a rift basin. When the subduction of the west Pacific plate became steeper, the subduction zone retreated to the east, and the melted material in the mantle extended continuously eastward. As the mantle cooled, the Songliao basin underwent subsidence and developed as a depression basin.

Acknowledgments Waveform data for this study are provided by Data Management Center of China National Seismic Networks at Institute of Geophysics, China Earthquake Administration (SEISDMC, doi:10.7914/SN/CB). And we also thank NECESSA Array group for sharing their data. We are also grateful anonymous reviewers for their valuable comments and suggestions. This work was supported by the National Natural Science Foundation of China (Grant No. 41274088), International Science and Technology Cooperation Program of China (ISCTP) (Grant No.2011DFB20210), and the Earthquake Science and Technology Spark Plan Project of Hebei province, China (Grant NO.DZ20150420030).

Open Access This article is distributed under the terms of the Creative Commons Attribution 4.0 International License (http://creativecommons.org/licenses/by/4.0/), which permits unrestricted use, distribution, and reproduction in any medium, provided you give appropriate credit to the original author(s) and the source, provide a link to the Creative Commons license, and indicate if changes were made.

\section{References}

Gao YG, Li YH (2014) Crustal thickness and $V \mathrm{p} / V \mathrm{~s}$ in the Northeast Chviina-North China region and its geological implication. Chin J Geophys 57(3):847-857. doi:10.6038/cig20140314 (in Chinese with English abstract)

Hu WS, Cai CF, Wu ZY, Li JM (1998) Structural style and its relation to hydrocarbon exploration in the Songliao Basin, Northeast China. Mar Petroleum Geol 15:41-55 (in Chinese with English abstract)

Kennett BLN, Engdahl ER (1991) Travel times for global earthquake location and phase identification. Geophys J Int 105(2):429-465

Lei JS, Zhao DP (2005) P-wave tomography and origin of the Changbai intraplate volcano in Northeast Asia. Tectonophysics 397(3-4):281-295

Li Y (2013) The impact on the Northeast and North China caused by the Tohoku-Oki Earthquake in Japan in 2011. Master Dissertation. Beijing, Institute of Geology, China Earthquake Administration (in Chinese with English abstract)

Li C, van der Hilst RD (2010) Structure of the upper mantle and transition zone beneath Southeast Asia from travel time tomography. J Geophys Res 115:B07308. doi:10.1029/2009JB006882

Li C, van der Hilst RD, Toksoz MN (2006) Constraining P-wave velocity variations in the upper mantle beneath Southeast Asia. Phys Earth Planet Inter 154(2):180-195

Liu H, Niu F (2011) Receiver function study of the crustal structure of Northeast China: Seismic evidence for a mantle upwelling beneath the eastern flank of the Songliao Basin and the Changbaishan region. Earthq Sci 24:27-33. doi:10.1007/s11589-011-0766-6

Nie FJ (2004) Study on tectonic evolution and sequences stratigraphy and ridden traps for petroleum in Dougtumo District of the Songiiao Basin. Beijing, Institute of Geology, China Earthquake Administration (in Chinese with English abstract)

Paige CC. 1982. Saunders MA. Algorithm 583 LSQR: sparse linear equations and least squares problems. ACM Trans, 8(2):195-209

Pan JT, Li YH, Wu QJ, Yu DX (2014) Ambient noise tomography in northeast China. Chin J Geophys 57(3):812-821. doi:10.6038/ cjg20140311 (in Chinese with English abstract)

Rawlinson N, Kennett BLN (2004) Rapid estimation of relative and absolute delay times across a network by adaptive stacking. Geophys J Int 157(1):332-340

Ren JY, Tanaki K, Li ST, Zhang JX (2001) Late Mesozoic and Cenozoic rifting and its dynamic setting in Eastern China and adjacent areas. Tectonophysics 344:175-205

Shi L (2004) Study of the tectonic-thermal evolution of the Songliao basin and quantitative assessment of its geothermal resource: a case study on the Dumeng district. Ph.D Dissertation. GuangZhou, Guangzhou Institute of Geochemistry Chinese Academy of Sciences (in Chinese with English abstract)

Shu LS, MU YF, Wang B (2003) The oil gas bearing strata and the structure features in the Songliao Basin, NE China. J Stratigr 27(4):340-347

Song LZ, Zhao ZH, Jiao GH, Sun P, Luo X, Jiang XH, Wang ZH, Zeng FY, Liao WD (2010) Geochemical characteristics of Early Cretaceous volcanic rocks from Songliao basin, Northeast China, and its tectonic impications. Acta Petrol Sin 26(4):1182-1194

Sun L (2012) Velocity structure of uppermost mantle from Pn tomography and tomography of S-wave attenuation in Northeast China. Ph. D Dissertation. Beijing, Institute of Geophysics, China Earthquake Administration (in Chinese with English abstract)

Tang YC, Obayashi M, Niu FL, Grand SP, Chen John YS, Kawakatsu H, Tanaka S, Ning Y, Ni James F (2014) Changbaishan volcanism 
in northeast China linked to subduction-induced mantle upwelling. Nat Geosci 7:470-475. doi:10.1038/NEGO2166

VanDecar JC, Crosson RS (1990) Determination of teleseismic relative phase arrival times using multi-channel cross-correlation and least squares. Bull Seismol Soc Am 80(1):150-169

Wan SS (2012) The study on tectonic evolution in North Songliao Basin. Master Dissertation. Chengdu University of Technology, ChengDu (in Chinese with English abstract)

Wei D-Y, WU Yan-G, Huan H-F (2014) The Bouguer anomaly field source in North of Songliao Basin. North China Earthquake Sciences. 32(1):1-4. doi:10.3969/j.iassn.1003-1375.2014.01.001 (in Chinese with English abstract)

Wei W, Xu JD, Zhao DP, Shi YL (2012) East Asia mantle tomography: new insight into plate subduction and intraplate volacanism. J Asian Earth Sci 60:88-103. doi:10.1016/j.jseaes. 2012.08.001

Yang BJ, Tang JR, Li QX, Wang JM, Faisal SA, Li RL, Wang HZ, Li ZL, Zhang $H$ (2003) The reflection structure of the crust in Songliao basin uplifts and "disconnect" Moho interface. Sci China (Series D) 33(2):170-176
Yu WX, LU JL,Zhang QL, Wang BH, Zhang YX (2012) A study on petrological geochemistry of the early cretaceous volcanic rocks from Changling Rift,Songliao Basin,China. ACTA Mineral Sin, 32(1):83-92

Zhang FX, Wu QJ, Li YH (2013) The traveltime tomography study by teleseismic P wave data in the Northeast China area. Chin J Geophys 56(8):2690-2700. doi:10.6038/cjg20130818 (in Chinese with English abstract)

Zhang FX, Wu QJ, Li YH (2014) A travel time tomography study by telescismic $\mathrm{S}$ wave data in the Northeast China area. Chin J Geophys 57(1):88-101. doi:10.6038/cjg201410109 (in Chinese with English abstract)

Zhao DP (2004) Global tomographic images of mantle plumes and subducting slabs: insight into deep Earth dynamics. Phys Earth Planet Inter 146(1-2):3-34

Zheng XF, Ouyang B, Zhang DN, Yao ZX, Liang JH, Zheng J (2009) Technical system construction of Data Backup Center for China Seismograph Network and the data support to researches on the Wenchuan earthquake. Chin J Geophys 52(5):1412-1417. doi:10. 3969/j.issn.0001-5733.2009.05.031 (in Chinese with English abstract) 